\title{
Impact of irrigation variability on pasture production and beneficial water use
}

\author{
V.O. SNOW ${ }^{1}$, R.F. ZYSKOWSKI' ${ }^{2}$, R.J. MARTIN ${ }^{2}$, T.L. KNIGHT ${ }^{3}$, \\ R.N. GILLESPIE ${ }^{2}$, M.U. RIDDLE ${ }^{2}$, T.J. FRASER ${ }^{3}$ and S.M. THOMAS ${ }^{2}$ \\ ${ }^{1}$ AgResearch - Grasslands, Private Bag 11008, Palmerston North \\ ${ }^{2}$ Crop \& Food Research, Private Bag 4704, Christchurch \\ ${ }^{3}$ AgResearch - Lincoln, Private Bag 4749, Christchurch \\ Val.Snow@agresearch.co.nz
}

\begin{abstract}
As the availability of water for irrigation becomes more limiting it is important to use the available water effectively and all potential avenues for improving irrigation efficiency should be examined. Improving irrigation system uniformity can lead to production gains and less loss of water through drainage, but such data are difficult to collect experimentally. Here we examine the potential of using a pasture production model to explore the gains from increased irrigation evenness and different irrigation scheduling. Simulations were done with varying levels of irrigation inputs to account for spatial and temporal variability of irrigation but with the same total amount of water being applied to the paddock. All simulations were done under the assumption of no nitrogen limitation to growth and with soil and weather data appropriate for the Winchmore area. There was a relatively greater effect of irrigation uniformity on drainage than on pasture production. In reality uneven irrigation may lead to areas of the paddock where over-irrigation leaches nitrogen from the soil and pasture production becomes limited by nitrogen supply. The simulation results here were under the assumption of non-limiting nitrogen and it is likely that inclusion of a full nitrogen simulation would lead to different results. However the model shows potential for generating data needed to understand the benefits of improved irrigation uniformity.
\end{abstract}

Keywords: irrigation variability, LUCI, simulation modelling

\section{Introduction}

The availability of water for pastoral irrigation is becoming an increasing issue in several regions in New Zealand and it is important to use the available water effectively (Martin et al. 2006). There are several potential avenues for improving irrigation efficiency (Aqualinc Research Ltd 2006), including irrigator design and performance, and scheduling. However, measuring these experimentally in the field under conditions of variable and unpredictable rainfall is difficult and expensive in an operational pastoral system. A process-oriented model of pasture production is therefore a potentially useful tool to explore the potential gains from improved irrigation efficiency.

The objective of this study was to examine the potential for the LUCI-Pasture module (Jamieson et al. 2006) to model pasture production under various irrigation regimes. Such data could then be used to thoroughly examine the potential benefits of improved irrigation performance. This paper presents initial research comparing model outputs against production data from irrigated and water stressed pasture.

\section{Methods \\ Model description}

The LUCI framework model is a model of a flat paddock that can be started and run for an arbitrary length of time with any sequence of crops and pastures while keeping track of the state of the system and the leakage of water and nitrogen from the system (Jamieson et al. 2006). From a process point of view, many of the crop modules are based on the wheat model Sirius (Jamieson et al. 1998; Jamieson \& Semenov 2000) connected to a soil percolation and leaching model based on the cascade model of Addiscott and Whitmore (1991). Recently a pasture module has been added to the system to allow exploration of cropping sequences that include a pasture fallow. The pasture module is a simple crop module based on radiation-use efficiency, similar to that described by McCall and Bishop-Hurley (2003) but includes resource partitioning to roots as well as shoots similar to the routines used in Huth et al. (2001). LUCI-Pasture is dynamically responsive to water (McCall \& BishopHurley 2003) and nitrogen availability (Huth et al. 2001). Soil mineralisation was modelled using the Sirius mineralisation routines (Jamieson et al. 2006).

\section{Model testing}

Data for ryegrass production in 2006/07 from a rainshelter experiment (Knight et al. 2007) was used to test the ability of the model to mimic pasture production under varying availability of water. The experiment comprised a full irrigation treatment and several partial irrigation treatments but as only the full irrigation and the quarter irrigation showed substantial differences in growth (Martin et al. 2007; Fraser et al. 2007) only those treatments were used here. Briefly, the experiment was 
carried out under a rainshelter to allow complete control of the amount of water added. Irrigation in the full irrigation treatment (plots 7 and 18) was assessed by measuring the soil water storage every week and adding sufficient irrigation to bring the soil back to field capacity. The quarter irrigation (plots 20 and 24) received no water every 3 weeks in the 4-week cycle and in the fourth week received the same amount of water that the full irrigation treatment was scheduled to receive. The model predictions were compared against pasture production measured by cutting whenever pasture mass reached $2500 \mathrm{~kg} \mathrm{DM} / \mathrm{ha}$.

The model predictions were also compared with the monitoring data of Rickard and Radcliffe (1976). These data were collected from the Winchmore Irrigation Station between 1959 and 1970 using a cage cut technique (Radcliffe 1974). The daily weather data needed to run the model did not overlap with the measurement period so only a general comparison of long-term growth rates was possible.

\section{Climate and soil}

Daily weather data from Winchmore (latitude -43.79 , longitude 171.79) was obtained for the period from 1972 to 2005 . The modelling was done using properties appropriate for the Lismore stony silt loam (New Zealand Soil Bureau 1968), a soil typical of the Winchmore area.

\section{Irrigation variability}

The effect of irrigation non-uniformity was simulated for a moving-boom type irrigation system, for example a centre-pivot system. In these systems, the irrigation efficiency has the potential to be high, around $80-90 \%$ (Aqualinc Research Ltd 2006). However, because the boom is fixed, the same sprinklers irrigate the same spot every irrigation, so any variation between sprinklers will lead to consistent or stable spatial variation in the amount of water applied to a particular part of the paddock. Irrigation efficiency will also be reduced by shorter-term temporal wind effects, variation in pump performance and water pressure.

To mimic these effects the paddock was divided into 11 sections. Each of these sections received a set longterm irrigation input but with a spatial and temporal variability superimposed. Three levels of irrigation spatial variation were modelled: "none" where each section received the same long-term irrigation input; "moderate" where the long-term average irrigation input varied from $+30 \%$ to $-30 \%$ of the intended irrigation input and; "strong" where the irrigation input varied by $\pm 60 \%$. Superimposed on those spatial irrigation variability patterns was a short-term, irrigation-toirrigation, variability of $20 \%, 40 \%$, and $60 \%$ representing "low", "moderate", and "high" temporal variability.

\section{Irrigation scheduling}

The modelling was done assuming 'perfect' scheduling to replace water used according the Priestley-Taylor evapotranspiration estimate. Two schedules were created, one for a 7-day irrigation system and another for a 21-day cycle. The long- and short-term irrigation variability described above was superimposed on the irrigation schedule. The amount of water applied to the 11 sections of soil used to represent the spatial variability was constrained to ensure that, as a paddock-average, only the intended amount of water was applied.

\section{Other settings and outputs examined}

In the modelling, we applied sufficient fertiliser so that there was no nitrogen limitation to growth. The pasture was managed by cutting to $1800 \mathrm{~kg} \mathrm{DM} /$ ha every 21 days. Pasture production was assessed by averaging the pasture growth in the 11 sections to produce a paddock average on a daily basis before aggregating to monthly and annual averages. Modelled drainage from the sections of soil was treated in a similar manner. Simulations without irrigation were also done for comparative purposes.

\section{Results and Discussion \\ Comparison with rainshelter data}

Data collected from the rainshelter experiment (Knight et al. 2007) in 2006/07 were used to test the ability of the model to mimic the effects of water stress on pasture production. The only difference between the simulation settings for comparison against the treatments was the amount of water applied, as the rainshelter watering was based on actual soil moisture deficits and the model on potential soil water deficits.

The comparison is shown in Figure 1 as accumulated dry matter harvested from October 2006. There was a slight tendency for the model to over-predict pasture growth in the October-November period for the full irrigation treatment. This was because the pasture in the rainshelter was short of nitrogen during the spring of 2006 (Knight et al. 2007). On the whole, however, there was a good comparison between the model and the rainshelter trial given the simplicity of the model, and the settings used in these simulations were used in all further modelling. Also shown in Figure 1 is the modelled soil water stress factor for the quarter irrigation treatment. The factor is a 1 (no stress) to 0 (permanent wilting) scale indicating the relative degree of stress in the modelled pasture. While there are no direct data to compare this against it does illustrate the 
Figure 1 Comparison of (a) simulated (lines) pasture growth and data for the full and quarter irrigation treatments (symbols) in the rainshelter trial (Knight et al. 2007) with (b) the simulated degree of water stress (see text for an explanation) for the quarter irrigation treatment.

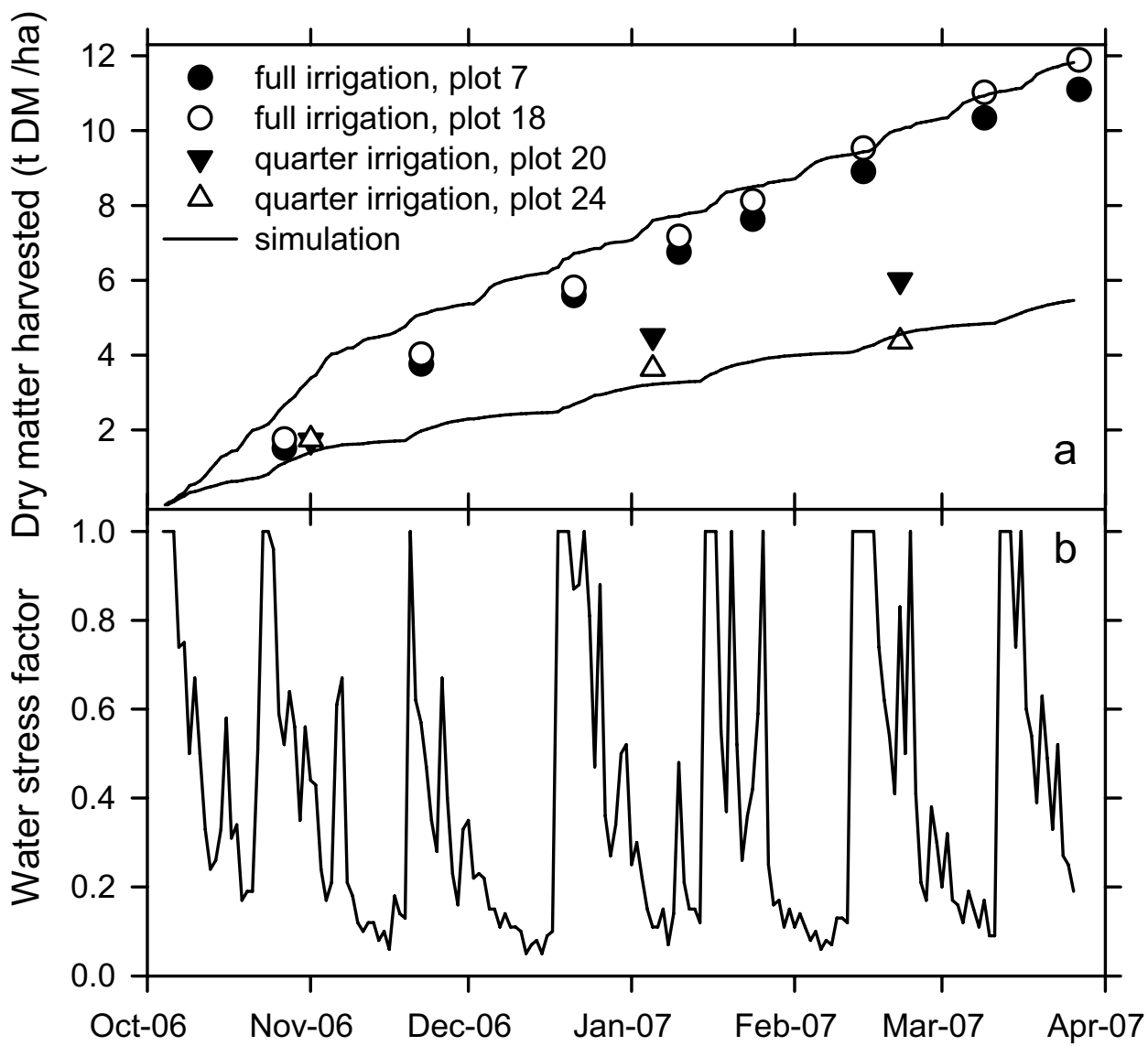

degree of water stress that was probably experienced by the pasture in the quarter irrigation treatment.

\section{Comparison with long term data}

Simulations were also done for 1972 to 2005 with no irrigation (Table 1). The mean annual yield in those simulations was $9.6 \mathrm{t} \mathrm{DM} / \mathrm{ha} / \mathrm{yr}$, ranging from 5 to 13.3 t DM/ha/yr. This is somewhat higher than the data collected by Rickard and Radcliffe (1976) between 1957 and 1970 which suggested an average dryland production of $5.9 \mathrm{t} \mathrm{DM} / \mathrm{ha} / \mathrm{yr}$. However the dryland simulation here was done with no nitrogen limitation and this would not have been the case in the Rickard \& Radcliffe (1976) data. The species in the pastures also included several older, lower yielding, pasture species and had some weed contribution (Rickard \& Radcliffe 1976). Given these factors we expect that the modelled pasture production should exceed that measured.

\section{Modelled drainage losses}

The modelled drainage losses for the 21-day irrigation schedule are shown in Figure 2. Similar results were seen in the 7-day irrigation schedule. Losses from all the modelled irrigated scenarios were higher than those

Table 1 Annual dry matter harvested (t DM/ha/yr) under dryland production from Rickard and Radcliffe (1976) and simulated by the LUCI-Pasture model.

\begin{tabular}{lcc}
\hline & Rickard \& Radcliffe (1976) data & LUCI-Pasture simulation \\
\hline Average & 5.9 & 9.6 \\
Std dev. & 1.1 & 2.0 \\
Range & $4.2-7.8$ & $5.0-13.3$ \\
Date range & $1958-1970$ & $1972-2005$ \\
\hline
\end{tabular}


Figure 2 Modelled annual drainage losses for the Lismore soil irrigated on a 21-day schedule for no, moderate and strong spatial variation and low, moderate and high temporal variability of irrigation.

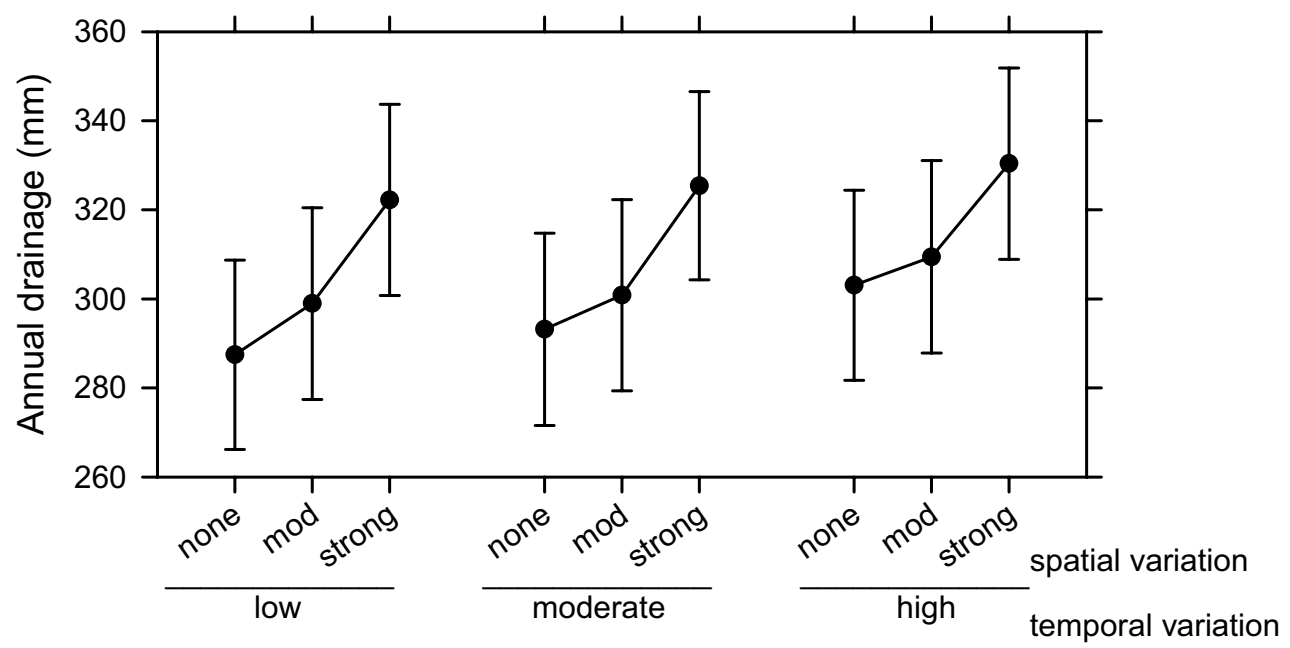

Figure 3 Modelled annual pasture production for the Lismore soil irrigated on a 7- or 21-day schedule for no, moderate and strong spatial irrigation variability and low, moderate and high temporal variability of irrigation. The boxes show the $25^{\text {th }}, 50^{\text {th }}$, and $75^{\text {th }}$ percentiles, the whiskers show the $5^{\text {th }}$ and $95^{\text {th }}$ percentiles and the symbols show the outliers.

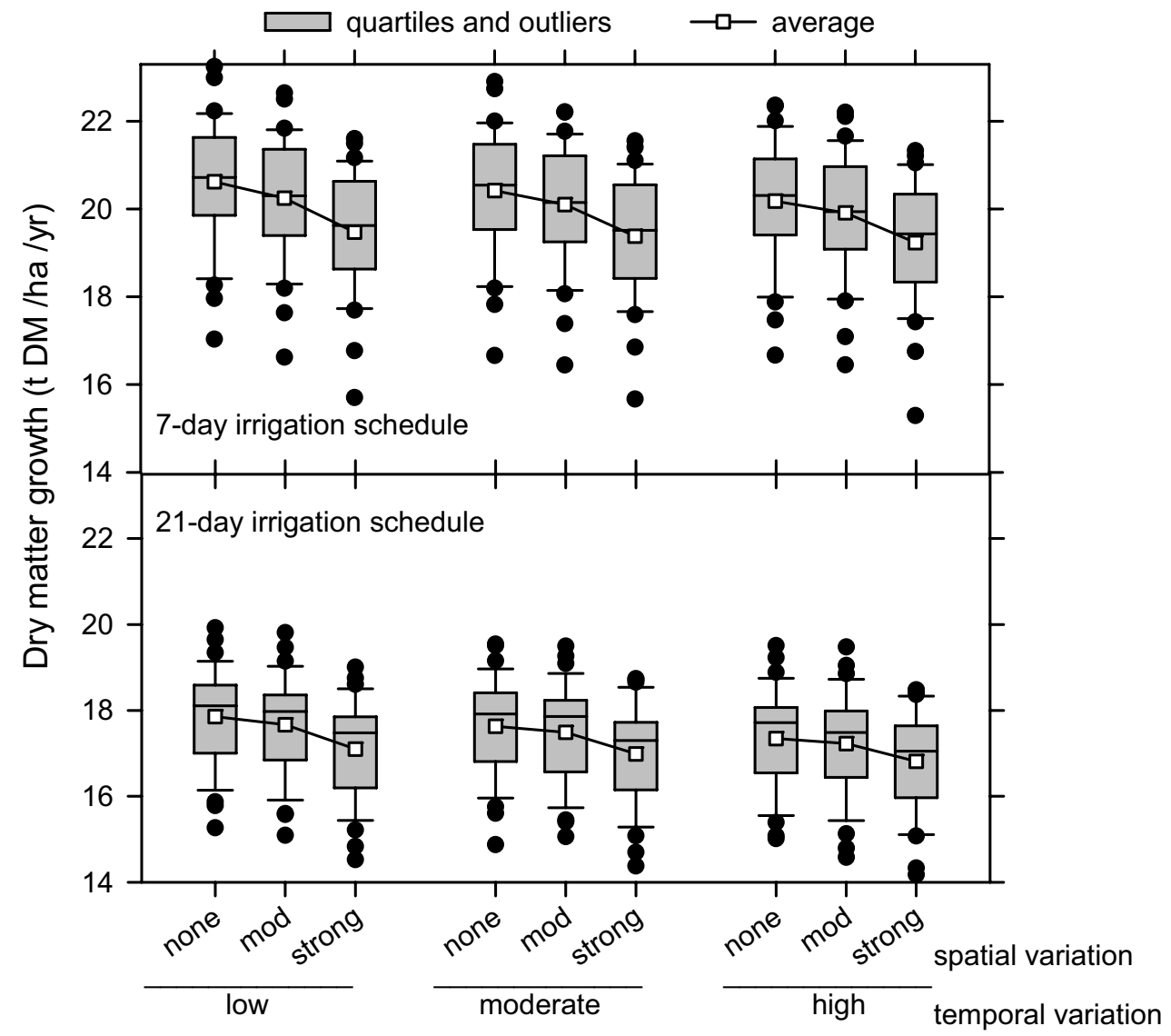


modelled from the dryland case (Table 1) which had an annual average drainage of $170 \mathrm{~mm} / \mathrm{yr}$. This is a result of an inevitable increase in drainage as the soil is kept nearer field capacity for an extended period of time, so increasing losses both from summer storms and in early winter.

The simulations suggest, as might be expected, that the lowest losses of water by drainage resulted when there was no spatial variability and low temporal variability in irrigation input. Increasing the short-term variability increased drainage but, with the range of variability used here, the spatial aspect of the variation had more effect than the temporal variation. While there is some evidence of an interaction between the spatial and temporal variation that affected drainage (Fig. 2) this is minor compared to the base effects.

\section{Modelled pasture production}

Modelled annual pasture production averaged 17.3 and $20.0 \mathrm{t} \mathrm{DM} /$ ha for the 21- and 7-day irrigation schedules (Fig. 3). Because the Lismore stony silt loam has a relatively low water storage (New Zealand Soil Bureau 1968), the pasture experienced some water stress between the irrigation events on the 21-day cycle. Assuming an $85 \%$ pasture utilisation, the modelled pasture production compares reasonably well with pasture consumption of about $17 \mathrm{t} \mathrm{DM} /$ ha measured on the Lincoln University Dairy Farm (www.siddc.org.nz/ludf.html, downloaded 22 May 2007). Annual production was more skewed (comparing the average to the median) for the 21-day schedule than for the 7-day schedule indicating that there was greater flexibility for pasture irrigated weekly to take advantage of the years with better growth conditions.

The highest pasture production on either irrigation schedule was obtained when there was no spatial irrigation variability and at the lowest level of temporal variability, with increasing variability of any sort decreasing pasture production although the effect was small (about $1 \mathrm{t} \mathrm{DM} / \mathrm{ha} / \mathrm{yr}$ in total). This relatively small effect on production was probably due to the constraints and limitations put on the system and these will be discussed further below.

\section{Constraints and limitations of these simulations}

In setting up the simulation study, two major assumptions were made. One of these was that all the simulations were done under conditions of no nitrogen limitation to growth. In practice, even if nitrogen is non-limiting for either the average or perfect irrigation case, it is likely that nitrogen could be limited under variable irrigation at either extreme of water input. Where there has been excessive input of water, drainage will remove nitrogen from the root zone, while in the parts of the soil that were under-irrigated, water stress will reduce mineralisation of the soil organic matter, perhaps also leading to increased nitrogen stress. Had all the simulations not been under conditions of non-limiting nitrogen there would probably have been a greater difference in simulated production between the 7- and 21-day irrigation schedules.

The second major assumption was that the same amount of water was applied in each simulation regardless of the degree and type of variability assumed. In practice, more water is applied as the irrigation variability increases (Aqualinc Research Ltd 2006), so increasing the amount of water lost as drainage. This too would have an interaction with nitrogen leaching and a nitrogen limitation to growth.

\section{Conclusions}

The purpose of this study was to examine the potential of a model to help understand the interaction between two types of irrigation variability and both pasture production and losses of water by drainage. While the model certainly does have potential in this direction, the current simulations are constrained by the need to run them under non-limiting nitrogen conditions. The assumption that the same amount of water would be applied in all simulations also constrained the results but was applied as a 'control' between simulations. Although the simulations here are only of a preliminary nature, they indicate that irrigation variability may have a stronger effect on the amount of water lost to drainage than on pasture production. Further work will add in the effects of nitrogen limitation and will also examine the implications of irrigation variability on nitrate leaching.

\section{ACKNOWLEDGEMENTS}

This work was funded under FRST contract C02X0304 "Land Use Change and Intensification"

\section{REFERENCES}

Addiscott, T.M.; Whitmore, A.P. 1991. Simulation of solute leaching in soils of differing permeabilities. Soil Use and Management 7: 94-102.

Aqualinc Research Ltd. 2006. Irrigation Efficiency Gaps - Review and Stock Take. Prepared for Sustainable Farming Fund and Irrigation New Zealand. Report No L05264/2. www.maf.govt.nz/sff/whats-on/ irrigation-efficiency-gaps.pdf, downloaded 7/4/07.

Huth, N.I.; Snow, V.O.; Keating, B.A. 2001. Integrating a forest modelling capability into an agricultural production systems modelling environment - Current applications and future possibilities. pp. 1895-1900. In: Proceedings of the International Congress on Modelling and Simulation, Australian National University, December 2001.

Jamieson, P.D.; Semenov, M.A. 2000. Modelling nitrogen uptake and redistribution in wheat. Field Crops 
Research 68: 21-29.

Jamieson, P.D.; Semenov, M.A.; Brooking, I.R.; Francis, G.S. 1998. Sirius: a mechanistic model of wheat response to environmental variation. European Journal of Agronomy 8: 161-179.

Jamieson, P.D.; Zyskowski, R.F.; Li, F.Y.; Francis, G.S.; Snow, V.O.; Lilburne, L. 2006. LUCI in the sky with diamonds - modelling the wider impacts of land use change and intensification. Proceedings of 13th Agronomy Conference 2006, 10-14 September 2006, Perth, Western Australia. Australian Society of Agronomy. http://www.regional.org.au/au/ a s a $/ 2006 / \mathrm{p} 1 \mathrm{enary} / \mathrm{technology/}$ 4603 jamiesonp.htm\#TopOfPage

Knight, T.L.; Martin, R.J.; Fraser, T.J.; Gillespie, R.N.; Riddle, M.U. 2007. Ryegrass and tall fescue forage production and water use efficiency under a range of water application frequencies. Agronomy New Zealand: in press

Martin, R.J.; Riddle, M.U.; Gillespie, R.N.; Knight, T.L.; Fraser, T.J.; Clark-Hill, W.J. 2007. Water use and growth of pastures 2005-06. Crop and Food Research Confidential Report No 1809.

Martin, R.J.; Thomas, S.M.; Stevens, D.R.; Zyskowski, R.F.; Moot, D.J.; Fraser, T.J. 2006. Improving water use efficiency on irrigated dairy farms in Canterbury. Proceedings of the New Zealand Grasslands Association 68: 155-160.

McCall, D.G.; Bishop-Hurley, G.J. 2003. A pasture growth model for use in a whole-farm diary production model. Agricultural Systems 76: 1183-1205.

New Zealand Soil Bureau 1968. Soils of New Zealand. Part 3, New Zealand Soil Bureau Bulletin. No. 26

Radcliffe, J.E. 1974. Seasonal distribution of pasture production in New Zealand. 1. Methods of measurement. New Zealand Journal of Experimental Agriculture 2: 337-340.

Rickard, D.S.; Radcliffe, J.E. 1976. Seasonal distribution of pasture production in New Zealand. XII. Winchmore, Canterbury Plains dryland and irrigated pastures. New Zealand Journal of Experimental Agriculture 4: 329335 . 